Journal of Engineering and Applied Sciences 14 (Special Issue 9): 10711-10715, 2019

ISSN: 1816-949X

(C) Medwell Journals, 2019

\title{
Green Synthesis of Cuonanoparticles by Olive Leaf Extract and use in Preparation Solar Cell
}

\author{
${ }^{1}$ Hamdia Hateem Al-Shammary, ${ }^{2}$ Kadhim A. Aadim, ${ }^{3}$ Radea H. Al-Shammari, \\ ${ }^{4}$ Waleed Madhloom Khalaf, ${ }^{1}$ Moaed Saleh Mohammed, \\ ${ }^{1}$ Marwa Shaker Mahmood and ${ }^{1}$ Nafeesa Jabbar Kadhim \\ ${ }^{1}$ Department of Chemistry, College of Science for Women, University of Baghdad, Baghdad, Iraq \\ ${ }^{2}$ Department of Physical, College of Science, University of Baghdad, Baghdad, Iraq \\ ${ }^{3}$ Department of Physical, College Education, Mustansiriya University, Baghdad, Iraq \\ ${ }^{4}$ Police College, Ministry of Interior, Baghdad, Iraq
}

\begin{abstract}
Research on green production methods for metal oxide Nanoparticles (NPs) is growing with the objective to overcome the potential hazards of these chemicals for a safer environment. In this study, facile, eco friendly synthesis of Copper Oxide (CuO) nanoparticles was successfully achieved using olive leaf extract. Nanoparticles were further characterized by Scanning Electron Microscopy (SEM), Energy Dispersive X-ray (EDX), Fourier Transforms Infrared Spectroscopy (FTIR), Atomic Force Microscope (AFM). Plant-mediated $\mathrm{CuO}$ nanoparticles were found to be oval shaped and well dispersed in suspension. Copper oxide nanoparticles are used in many applications, therefore, these green synthesized CuO NPs are application in prepare solar cell give.
\end{abstract}

Key words: Nanoparticles, copper oxide, SEM, FTIR, EDX

\section{INTRODUCTION}

Cupric Oxide $(\mathrm{CuO})$ is one of the very attractive semiconducting materials a p-type semiconductor with a narrow band gap of $1.2 \mathrm{eV}$ (Chen et al., 2013). Owing to its many superior characteristics, for example, good thermal stability, electrical conductivity and optical properties, $\mathrm{CuO}$ has found widespread applications in different fields like photocatalysis (Devi and Singh, 2014; Bhattacharjee and Ahmaruzzaman, 2016; Akhavan et al., 2011), superconductivity (Eibl, 1993), solar energy harvesting (Rakhshani, 1986), energy storage (lithium ion batteries) (Wang et al., 2009) and antimicrobial devices (Ren et al., 2009). Moreover, the efficiency of $\mathrm{CuO}$ materials has been improved by nano structuring their particle size for this purpose different methods have been adopted and/or developed which helped in getting $\mathrm{CuO}$ materials in diverse morphologies (Safa et al., 2016). Some of these classical methods are sol-gel, coprecipitation, electrochemical, solvothermal/ hydrothermal, sonochemical, solid state synthesis and microwave irradiation (Borkow and Gabbay, 2009). However, harmful chemicals are either used during manipulations or produced as byproducts in nearly all these methods. Consequently, synthesis of $\mathrm{CuO}$ by one of these methods poses serious threats to the environment. To avoid the dangers posed by the use of harmful chemicals and/or produced as by products, green synthesis of NPs is gaining tremendous attention (Sharma et al., 2015). Besides, it is simple, no expensive and environment friendly. CuO NPs have been prepared using different plants which influence the morphology of the resulting nanomaterial (Fan et al., 2003; Xu et al., 2002). In fact the plant extracts act as reducing and capping agents to direct the structure of the resulting NPs (Sharma et al., 2015). Following the principles of green chemistry, here we report upon the construction of CuO NPs by using extracts of different vegetables (Cauliflowers, Potatoes and Peas peels) wastes and exploration of their microstructure, morphology and optical properties.

Green chemistry focuses on the production of desired products without generation of hazardous intermediate byproducts in chemical reaction processes. Integrating green chemistry principles into nanotechnology has led to the identification of environmentally friendly reagents that are multifunctional in that they can serve as a reducing agent as well as a capping agent (Iravani, 2011; Han et al., 2013). Synthesis of Nanoparticles (NPs) can be performed using a number of routinely used chemical and physical methods (Ershov et al., 1991). Plants and their related materials for production of nanomaterials are not only ecofriendly alternatives but they are also cost effective. Synthesis of Copper Oxide (CuO) nanoparticles has been performed using extracts of soybeans (Dhas et al., 1998), gum karaya (Feldmann and

Corresponding Author: Hamdia Hateem Al-Shammary, Department of Chemistry, College of Science for Women, University of Baghdad, Baghdad, Iraq 
Jungk, 2001), bark extract (Stopic et al., 2005), leaf extract (Xiong et al., 2011; Guajardo-Pacheco et al., 2010), fruit (Padil and Cernik, 2013; Yallappa et al., 2013), tea and coffee powder (Angajala et al., 2014), peel extract (Naika et al., 2015) and flower extract (Sankar et al., 2014). Development in large-scale production for both metallic and nonmetallic nanoparticles has introduced risk to the environment and human health (Viswadevarayalu et al., 2016; Sutradhar et al., 2014). Improper disposal of nanomaterial waste by labs as well as industry is an alarming threat to the ecosystem as well as aquatic life. With this perspective, researchers are focusing on the green synthesis of nanomaterials. The aim is to protect the environment and human health from toxic impacts of nanomaterials and their derived complex compounds and at the same time safely utilize nanomaterials. Environmental and biological risks for copper nanoparticles have been investigated by many researchers. Synthesized nanoparticles by leaf extract of Pterospermum acerifolium which is an angiosperm belonging to the family Malavacea distributed in Southeast Asia (Karimi and Mohsenzadeh, 2015). The aim is to protect the environment and human health from toxic impacts of nanomaterials and their derived complex compounds and at the same time safely utilize nanomaterials. Environmental and biological risks for copper nanoparticles have been investigated by many researchers. However, the toxicity of nanosized and bulk $\mathrm{CuO}$ metal oxide nanoparticles to bacteria (Rispoli et al., 2010). In recent years, they are receiving lot of attention for their versatile properties andpotential use as gas sensors, solar cells, lithium ion batteries and heterogeneous catalysts (Rakhshani, 1986).

\section{MATERIALS AND METHODS}

Experimental (preparation of olive leaf extract): To prepare the leaf extract of olive leaf extract ( $25 \mathrm{~g}$ ) were thoroughly washed, dried and finely chopped. The finely, chopped material was allowed to boil for $5 \mathrm{~min}$ at $80^{\circ} \mathrm{C}$ with $100 \mathrm{~mL}$ of de-ionized water in a 250-mL Erlenmeyer flask and then cooled down to room temperature. The resulting solution is passed through a filter paper to remove any solid particles and then again filtered through a Whatman filter paper of pore size $0.2 \mu \mathrm{m}$. The filtrate is stored at $4^{\circ} \mathrm{C}$ as a stock for the synthesis of CuO NPs.

As fifty milliliters of $10 \mathrm{~mm}$ aqueous solution of copper nitrate (99.99\% purity, Aldrich) was added to $5 \mathrm{~mL}$ finely chopped in a $100 \mathrm{~mL}$ Erlenmeyer flask with constant stirring on a magnetic stirrer at $100-120^{\circ} \mathrm{C}$. Colour change of the reaction mixture was observed from deep blue to colourless and then to brick red and dark red on vigorous stirring for $24 \mathrm{~h}$. Then the resultant solution is centrifuged at $10,000 \mathrm{rpm}$ for $10 \mathrm{~min}$ at room temperature (using Beckman centrifuge with a Beckman JA-17 rotor) and the mixture is collected after discarding the supernatant. The collected CuO NPs are allowed to dry in a watch glass. The formed black

Where a solar cell was prepared from target of the deposition of nano $\mathrm{CuO}$, it was mix $\left(\mathrm{Ag}_{2} \mathrm{O}\right.$ and $\left.\mathrm{CuO}\right)$ in the rate of $(1.2 / 1.8)$ on series, shaped liked disc with a diameter of $1 \mathrm{~cm}$. Using the deposition method (PLD), $\left(\mathrm{Ag}_{2} \mathrm{O}\right.$ and $\left.\mathrm{CuO}\right)$ film on substrate Ps, the influence of laser energy was (600-1000 mJ). The substrate and target inside vacuum at a pressure of $10^{-3} \mathrm{mbar}$. The substrate was placed at $3 \mathrm{~cm}$ from the $\left(\mathrm{Ag}_{2} \mathrm{O}\right.$ and $\left.\mathrm{CuO}\right)$ target, the $\left(\mathrm{Ag}_{2} \mathrm{O}\right.$ and $\mathrm{CuO}$ ) target it is bombarded by 400 pulses by 10-30 sec to obtain a one layer of film. During the deposition was fired using a Nd:YAG laser operating under specific energy. The Nd:YAG laser with a fundamental harmonic frequency $(\lambda=1064 \mathrm{~nm}, 10 \mathrm{nsec}$, $6 \mathrm{~Hz})$ is focused on a $\left(\mathrm{Ag}_{2} \mathrm{O}\right.$ and $\left.\mathrm{CuO}\right)$ target with a quartz lens. The laser beam is focused on the target by an angle of incidence of $45^{\circ}$. The study their influenceof laser energy on the of solar cell of $\left(\mathrm{Ag}_{2} \mathrm{O}\right.$ and $\left.\mathrm{CuO}\right)$ and properties of the deposited film.

Characterization of synthesized CuONPs: The morphological, structural and chemical composition of $\mathrm{CuO}$ NPs were analyzed by employing SEM-EDS INSPECT S50) and XRD (PAN analytical: XPERT-PRO) equipment. Through FTIR (Shimadzu FTIR Prestige 21). AFM (SPM Scanning Probe Microscope) and and UV-Vis (Shimadzu UV-Vis 2450) spectroscopy spectral analysis.

\section{RESULTS AND DISCUSSION}

UV-Vis and FTIR: Figure 1-4 shows UV spectra of $\mathrm{CuO}$ NPs using olive leaf extract. The colloidal suspension after reduction showed two strong resonances, one is in between 265-285 $\mathrm{nm}$ and another weak but broad resonance centered at about $670 \mathrm{~nm}$ indicating the formation of $\mathrm{CuO}$ NPs. The peak at $260 \mathrm{~nm}$ is due to inter-band transition of core electrons of copper metal, while that of peak around $670 \mathrm{~nm}$ and corresponds band edge transition of Cupric Oxide (CuO). FTIR spectra were recorded in solid phase using the $\mathrm{KBr}$ pellet technique in the range of $4000-400 \mathrm{~cm}^{-1}$. FTIR analysis Fig. 5 of green synthesized $\mathrm{CuO}$ nanoparticles revealed a strong band at $1100 \mathrm{~cm}^{-1}$ whereas peaks at $529 \mathrm{~cm}^{-1}$ can be attributed to vibrations of $\mathrm{CuO}$, confirming the formation of highly pure $\mathrm{CuO}$ nanoparticles (Ren et al., 2009). The bands around 3450, 1600 and $2350 \mathrm{~cm}^{-1}$ show the presence of $-\mathrm{OH}, \mathrm{C}-\mathrm{C}$ and $\mathrm{C}=\mathrm{O}$ stretching of hydroxyl groups, alkenes and presence of alkanes, respectively.

2-2-atomic force microscope: The AFM analysis provides the measurements of average grain size (Fig. 3). 

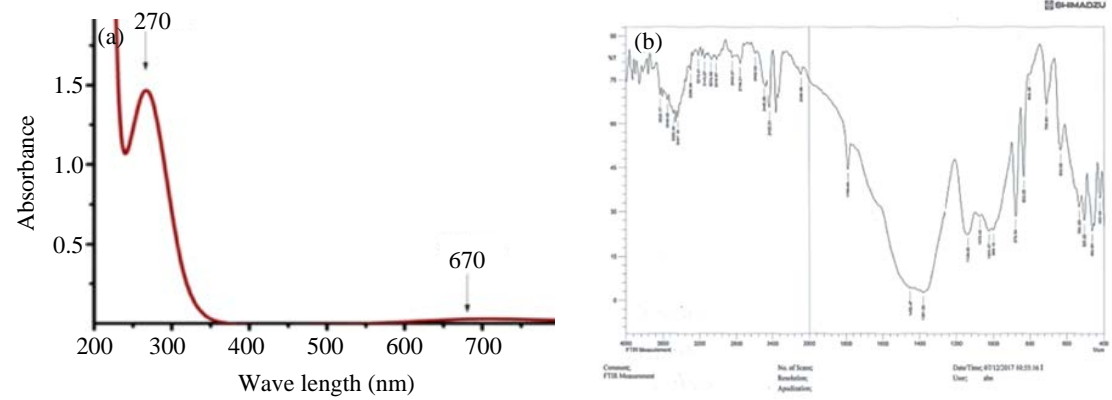

Fig. 1(a, b): UV spectra and FTIR spectraof CuONPs
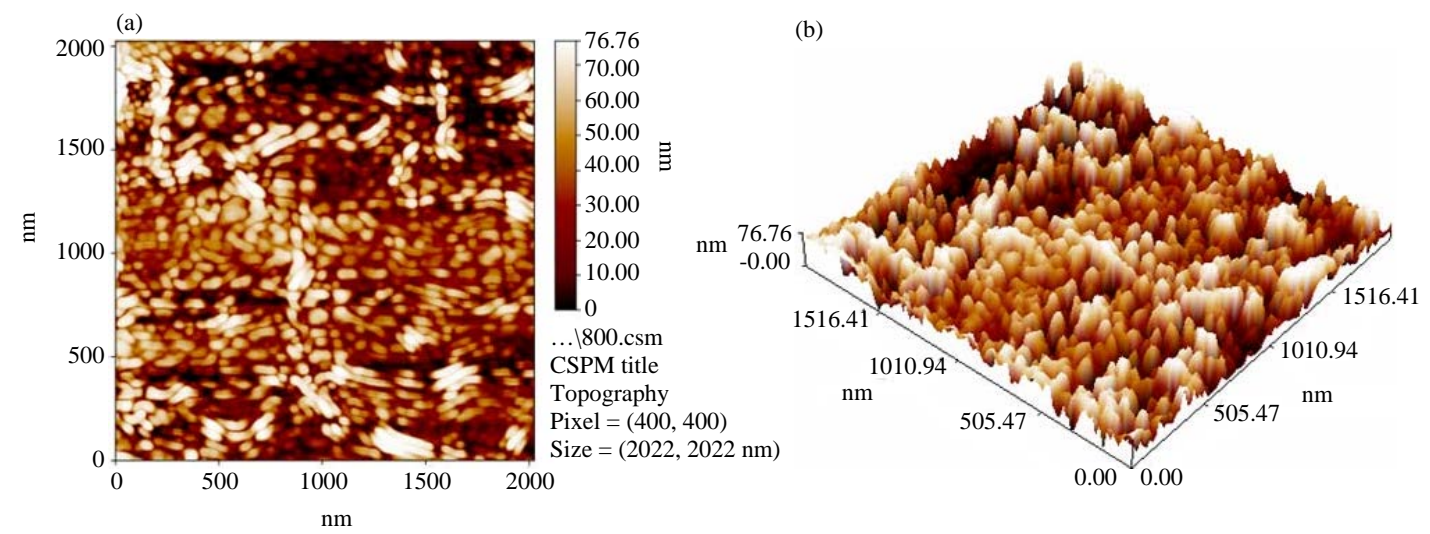

Fig. 2(a, b): AFM image of $\mathrm{CuO}$

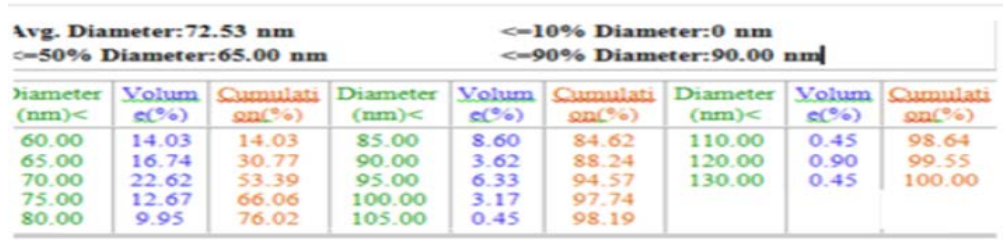

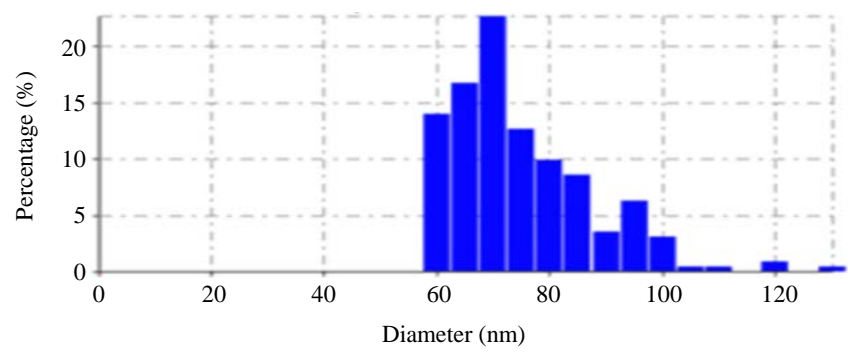

Fig. 3: The measurements of average grain size of $\mathrm{CuO}$

Figure 2 shows typical surface AFM image (a: in tow and $\mathrm{b}$ : in three dimensional) and the granularity cumulating distribution for $\mathrm{CuO}$. The average diameter is $72 \mathrm{~nm}$ for $\mathrm{CuO}$.

$\mathrm{X}$-ray diffraction and scanning electron micrograph: The XRD technique was used to determine and confirm thecrystal structure of the nanoparticles. XRD analysis showed aseries of diffraction peaks at $2 \theta$ of $32.41,35.61$, 38.81, 48.91, 53.31, 58.21, 61.61 and 66.31. The XRD spectrum clearly suggested the crystallinenature of the $\mathrm{CuO}$ NPs synthesized from leaf extract ofOlive Leaf Extract. The peak positions exhibited the monoclinic structure of $\mathrm{CuO}$ which was confirmed by the International Centre for Diffraction Data (ICDD) card no. 801916 Fig. 4. 
J. Eng. Applied Sci., 14 (Special Issue 9): 10711-10715, 2019

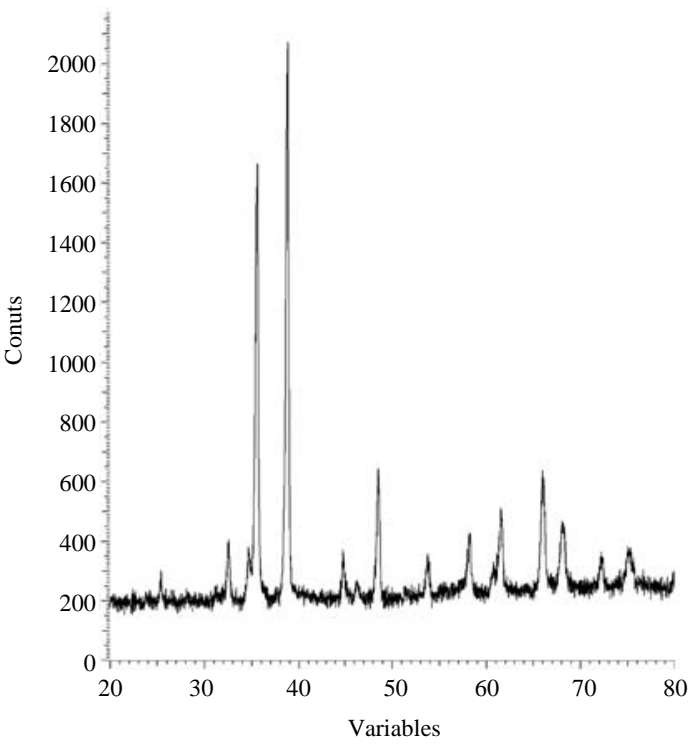

Fig. 4: XRD patterns of pure $\mathrm{CuO}$

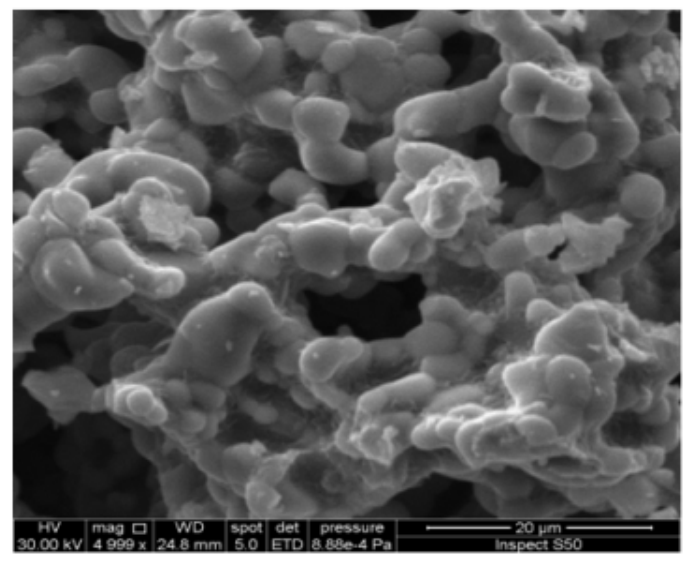

Fig. 5: Scanning electron micrograph

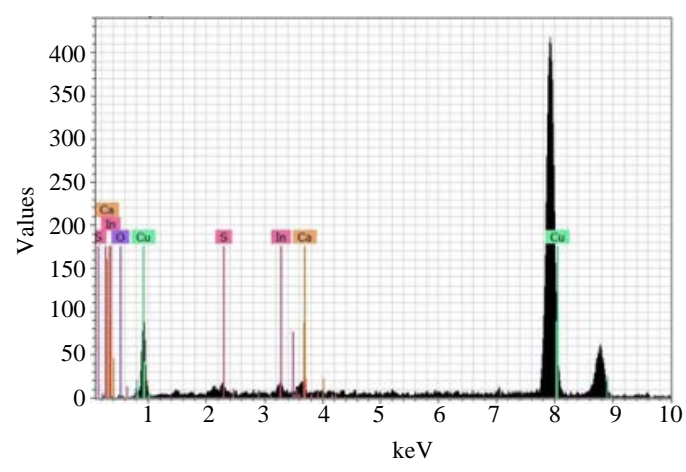

Fig. 6: EDX analysis

SEM image (Fig. 5) of $\mathrm{CuO}$ nanoparticles showed the presence of some large particles which can be
Table 1: V-I characteristics of solar cell

\begin{tabular}{lcccc}
\hline Influence of laser energy $(\mathrm{mJ})$ & $\mathrm{Jsc}\left(\mathrm{mA} / \mathrm{cm}^{2}\right)$ & Voc $(\mathrm{V})$ & F.F & $\% \eta$ \\
\hline 1000 & 5 & 0.53 & 0.648 & 1.71 \\
900 & 4.8 & 0.54 & 0.617 & 1.60 \\
800 & 4.9 & 0.48 & 0.538 & 1.26 \\
700 & 4.82 & 0.51 & 0.488 & 1.20 \\
600 & 4.7 & 0.49 & 0.500 & 1.15 \\
\hline
\end{tabular}

attributed to aggregation or overlapping of smaller particles with sizesaround $100 \mathrm{~nm}$, the morphology of $\mathrm{CuO}$ is appear nanorod. The EDS analysis revealed the chemical composition of the nanoparticles having atomic percent of $54 \%$ for $\mathrm{Cu}$ and $45 \%$ for O (Fig. 6 and Table 1).

\section{CONCLUSION}

In summary, the green synthesis of CuO NPs was carried outby using Olive Leaf Extractsingly without the involvement ofany other chemical reagent. XRD, SEM and AFM analysis conformed that the CuO NPs show to an average grain size of $70 \mathrm{~nm}$. These green synthesized $\mathrm{CuO}$ NPs are application in prepare solar cell give.

\section{REFERENCES}

Akhavan, O., R. Azimirad, S. Safa and E. Hasani, 2011. $\mathrm{CuO} / \mathrm{Cu}(\mathrm{OH}) 2$ hierarchical nanostructures as bactericidal photocatalysts. J. Mater. Chem., 21: 9634-9640.

Angajala, G., P. Pavan and R. Subashini, 2014. One-step biofabrication of copper nanoparticles from Aegle marmelos correa aqueous leaf extract and evaluation of its anti-inflammatory and mosquito larvicidal efficacy. RSC. Adv., 4: 51459-51470.

Bhattacharjee, A. and M. Ahmaruzzaman, 2016. CuO nanostructures: Facile synthesis and applications for enhanced photodegradation of organic compounds and reduction of p-nitrophenol from aqueous phase. RSC. Adv., 6: 41348-41363.

Borkow, G. and J. Gabbay, 2009. Copper, an ancient remedy returning to fight microbial, fungal and viral infections. Curr. Chem. Biol., 3: 272-278.

Chen, H., G. Zhao and Y. Liu, 2013. Low-temperature solution synthesis of $\mathrm{CuO}$ nanorods with thin diameter. Mater. Lett., 93: 60-63.

Devi, H.S. and T.D. Singh, 2014. Synthesis of copper oxide nanoparticles by a novel method and its application in the degradation of methyl orange. Adv. Electron. Electr. Eng., 4: 83-88.

Dhas, N.A., C.P. Raj and A. Gedanken, 1998. Synthesis, characterization and properties of metallic copper nanoparticles. Chem. Mater., 10: 1446-1452. 
Eibl, O., 1993. Application of a new method for absorption correction in high-accuracy, quantitative EDX microanalysis in the TEM: Analysis of oxygen in CuO-based high-Tc superconductors. Ultramicroscopy, 50: 189-201.

Ershov, B.G., E. Janata, M. Michaelis and A. Henglein, 1991. Reduction of aqueous copper $(2+)$ by carbon dioxide (1-): First steps and the formation of colloidal copper. J. Phys. Chem., 95: 8996-8999.

Fan, H., L. Yang, W. Hua, X. Wu and Z. Wu et al., 2003. Controlled synthesis of monodispersed $\mathrm{CuO}$ nanocrystals. Nanotechnol., 15: 37-42.

Feldmann, C. and H.O. Jungk, 2001. Polyol-mediated preparation of nanoscale oxide particles. Angew. Chem. Intl. Ed., 40: 359-362.

Guajardo-Pacheco, M.J., J.E. Morales-Sanchez, J. Gonzalez-Hernandez and F. Ruiz, 2010. Synthesis of copper nanoparticles using soybeans as a chelant agent. Mater. Lett., 64: 1361-1364.

Han, C., M. Pelaez, Nadagouda, M.N. Obare and S.O. Falaras et al., 2013. The Green Synthesis and Environmental Applications of Nanomaterials. In: Sustainable Preparation of Metal Nanoparticles: Methods and Applications, Luque, R. and R.S. Varma (Eds.). The Royal Society of Chemistry, London, UK., ISBN:978-1-84973-428-8, pp: 106-143.

Iravani, S., 2011. Green synthesis of metal nanoparticles using plants. Green Chem., 13: 2638-2650.

Karimi, J. and S. Mohsenzadeh, 2015. Rapid, green and eco-friendly biosynthesis of copper nanoparticles using flower extract of Aloe vera. Synth. React. Inorg. Metal Org. Nano Metal Chem., 45: 895-898.

Naika, H.R., K. Lingaraju, K. Manjunath, D. Kumar and G. Nagaraju et al., 2015. Green synthesis of $\mathrm{CuO}$ nanoparticles using Gloriosa superb L. extract and their antibacterial activity. J. Taibah Univ. Sci., 9: 7-12.

Padil, V.V.T. and M. Cernik, 2013. Green synthesis of copper oxide nanoparticles using gum karaya as a biotemplate and their antibacterial application. Int. J. Nanomed., 8: 889-898.

Rakhshani, A.E., 1986. Preparation, characteristics and photovoltaic properties of cuprous oxide-a review. Solid State Electron., 29: 7-17.

Ren, G., D. Hu, E.W.C. Cheng, M.A. Vargas-Reus and P. Reip et al., 2009. Characterisation of copper oxide nanoparticles for antimicrobial applications. Intl. J. Antimicrob. Agents, 33: 587-590.

Rispoli, F., A. Angelov, D. Badia, A. Kumar and S. Seal et al., 2010. Understanding the toxicity of aggregated zero valent copper nanoparticles against Escherichia coli. J. Hazard. Mater., 180: 212-216.
Safa, S., R. Azimirad, S.S. Moghaddam and M. Rabbani, 2016. Investigating on photocatalytic performance of $\mathrm{CuO}$ micro and nanostructures prepared by different precursors. Desalin. Water Treat., 57: 6723-6731.

Sankar, R., P. Manikandan, V. Malarvizhi, T. Fathima, K.S. Shivashangari and V. Ravikumar, 2014. Green synthesis of colloidal copper oxide nanoparticles using Carica papaya and its application in photocatalytic dye degradation. Spectrochim. Acta Part A: Mol. Biomol. Spectrosc., 121: 746-750.

Sharma, J.K., M.S. Akhtar, S. Ameen, P. Srivastava and G. Singh, 2015. Green synthesis of $\mathrm{CuO}$ nanoparticles with leaf extract of Calotropis gigantea and its dye-sensitized solar cells applications. J. Alloys Compd., 632: 321-325.

Stopic, S., P. Dvorak and B. Friedrich, 2005. Synthesis of spherical nanosized copper powder by ultrasonic spray pyrolysis. World Metall. ERZMETALL., 58: 195-201.

Sutradhar, P., M. Saha and D. Maiti, 2014. Microwave synthesis of copper oxide nanoparticles using tea leaf and coffee powder extracts and its antibacterial activity. J. Nanostructure Chem., 4: 1-6.

Viswadevarayalu, A., P.V. Ramana, G.S. Kumar, L.R. Sylvia and J. Sumalatha et al., 2016. Fine ultrasmall copper nanoparticle (UCuNPs) synthesis by using Terminalia bellirica fruit extract and its antimicrobial activity. J. Cluster Sci., 27: $155-168$.

Wang, H., Q. Pan, J. Zhao and W. Chen, 2009. Fabrication of $\mathrm{CuO} / \mathrm{C}$ films with sisal-like hierarchical microstructures and its application in lithium ion batteries. J. Alloys Compd., 476: 408-413.

Wasfi, M., 2011. Solar energy and photovoltaic systems. J. Sel. Areas Renewable Sustainable Energy, 1: 1-8.

Xiong, J., Y. Wang, Q. Xue and X. Wu, 2011. Synthesis of highly stable dispersions of nanosized copper particles using L-ascorbic acid. Green Chem., 13: 900-904.

Xu, C., Y. Liu, G. Xu and G. Wang, 2002. Preparation and characterization of $\mathrm{CuO}$ nanorods by thermal decomposition of CuC2O4 precursor. Mater. Res. Bull., 37: 2365-2372.

Yallappa, S., J. Manjanna, M.A. Sindhe, N.D. Satyanarayan, S.N. Pramod and K. Nagaraja, 2013. Microwave assisted rapid synthesis and biological evaluation of stable copper nanoparticles using T. arjuna bark extract. Spectrochimica Acta Part A: Mol. Biomolecular Spectroscopy, 110: 108-115. 